\title{
DIALLEL ANALYSIS OF PHOTOSYNTHETIC RATE AND RELATED LEAF CHARACTERS AMONG CONTRASTING GENOTYPES OF LOLIUM PERENNE
}

\author{
D. WILSON* and J. P. COOPER \\ Welsh Plant Breeding Station, Aberystwyth
}

Received 21.i.69

\section{Introduction}

Growth analyses of seedling Lolium populations have demonstrated the existence of interpopulation differences in relative growth rate, associated with differences in net assimilation rate, in both weak and strong light (Wilson and Cooper, 1969a). At relatively high light intensities, populations with faster NAR had smaller mesophyll cells than those with slower (Wilson and Cooper, 1967). Further, among leaves from genotypes of these populations, apparent light-saturated photosynthesis was found to be negatively associated with size of mesophyll cells when plants had been grown in a common environment (Wilson and Cooper, 1969b). Using clonal material, differences between genotypes in efficiency of utilisation of weak light were also found (Wilson and Cooper, 1969b). A useful approach to the problem of breeding for yield might therefore be to use this variation in efficiency of light utilisation in the construction of a synthetic variety or the production of selection lines. For screening purposes, photosynthesis may be measured directly, but it may be more practical to use some closely related characteristic such as mesophyll cell size as a selection criterion.

The possibilities of utilising variation in any character depend on how much of the observed variation is genetic and additive. The existence of high levels of heterozygosity within $L$. perenne is well established (Cooper, 1959, 1961; Corkill, 1956) and marked response to selection from within different populations has been obtained for date of ear emergence, winter requirement for floral induction, leaf size and rate of leaf appearance (Cooper, 1961, 1963; Edwards and Cooper, 1963). The genetic basis of variation between unrelated genotypes or between different populations of $L$. perenne has been investigated by Corkill (1950), Breese (1960), Fejer (1960), Beddows et al. (1962), Thomas (1965, 1966) and Hayward and Breese (1968), often using diallel analysis.

Synthetic varieties of outbreeding pasture grasses are usually based on a number of unrelated plants to avoid inbreeding depression. The soundest basis on which to select parent plants for a synthetic variety is through a progeny test, which enables selection to be made on the genotype rather than the phenotype (Corkill, 1950). Both Corkill (1950) and Breese (1960) have demonstrated the suitability of the diallel cross as a means of genetic assessment of unrelated Lolium plants. Dickinson and Jinks (1956) and Breese (1968) have considered the implications of using non-inbred parents in genetic investigations adopting this crossing system, and point out that when heterozygous parents in a diallel cross are related, the analysis may be less

* Present address : Grasslands Division, D.S.I.R., Palmerston North, New Zealand. 
sensitive. On the other hand, crosses between plants from evolutionarily distinct populations may be expected to be equivalent for analysis purposes to crosses between "homozygous only" parents, when greatest sensitivity would be achieved.

In the present experiment, a half-diallel analysis is used to determine genetic variances and heritabilities for the photosynthetic rate and the associated anatomical and morphological characteristics of the leaf examined previously (Wilson and Cooper, 1969b). The analysis is also used to examine the feasibility of using laboratory determinations of photosynthesis and leaf anatomy in genetic studies and to examine the effects of various methods of analysis of the diallel.

\section{Materials AND METHODS}

A $6 \times 6$ half-diallel cross was performed among the following Lolium perenne genotypes:

Parental genotype

$20 / 15$

*6/15

$7 / 21$

$24 / 13$

$5 / 20$

$3 / 19$
Population of origin

variety, "Steinacher" Germany

variety, "Vertas hybrid long-rotation", Netherlands

ecotype, Badajos, C. Spain

variety, " Norlea " Canada

ecotype, Macedonia, $1500 \mathrm{~m}$. alt.

ecotype, Pamplona, Spanish Pyrenees, $450 \mathrm{~m}$. alt.

* Lolium (multiflorum $\times$ perenne) $\times$ perenne.

Because most $L$. perenne plants set only a limited amount of seed on selfing (Jenkin, 1931b), the crossing technique used was the method of automatic cross-pollination without emasculation (Jenkin, 1931a). Tests for selfcompatibility, using from 6 to 10 heads from different plants, were conducted at the same time as the crosses. For this purpose, heads from the same genotype were bagged together. However, selfing was found to be slight, ranging from no seeds in genotypes $7 / 21$ and $5 / 20$ to only three seeds per head in 24/13. This compared with a range in seeds per head of from 16 to 50 among the crosses.

The half-diallel involves all possible crosses between $n$ plants used as both male and female parents, but without reciprocals, i.e. $\frac{n(n+1)}{2}$ matings (Jinks and Hayman, 1953; Hayman, 1954a). However, because of the inbreeding depression which occurs in L. perenne on selfing (Jenkin, 1931b), parents were represented by clonally replicated material in the present experiments. Thus, there were $15 \mathrm{~F}_{1}$ families and six replicated parents.

Seed of each cross and its reciprocal was bulked to allow random sampling within each of the 15 families. Seed was sown in petri dishes, and germinated seedlings were later planted singly in 4-inch pots in John Innes No. 2 potting compost. At the same time, recently established plants of each parent were planted singly in pots in the same growth medium. Each family was represented by 10 plants and each parent by four, a total of 174 plants. These were split into two randomised blocks of five plants per family and two per 
parent. Each block of plants was grown in a separate controlled environment room in a nine-hour photoperiod: of $0.129 \mathrm{cal} . / \mathrm{cm} .{ }^{2} / \mathrm{min}$. of radiation in the spectral region $400-720 \mathrm{~m} \mu$ (1800 ft.-c.) provided by banks of Mazda warm-white $125 \mathrm{~W}$ fluorescent tubes, at $15^{\circ} \mathrm{C}$. The light period in one room started at $8.0 \mathrm{a} . \mathrm{m}$. and in the other, four hours later at noon. Thus plants could be sampled twice daily, once in each room, at the same time after the beginning of the light period (two hours).

Eight parameters were recorded in every progeny plant:

1. Apparent light-saturated photosynthesis of 6 th main stem leaf.

2. Apparent light-limited photosynthesis of 7 th main stem leaf.

3. Mean cross-sectional area per mesophyll cell (cell size) on 6th leaf.

4. Mean mesophyll thickness of 6 th leaf.

5. Leaf chlorophyll content of 7 th leaf.

6. Leaf width of 6 th and 7 th leaves.

7. Leaf length of 6 th and 7 th leaves.

8. Leaf size (length $\times$ width $\times 0.905$ ) of 6 th and 7 th leaves.

The same parameters were recorded on one randomly selected young fully expanded leaf from each plant of the parental genotypes.

Apparent photosynthesis of central leaf portions was measured manometrically (Wilson et al., 1969; Wilson and Cooper, 1969b) at $15^{\circ} \mathrm{C}$. with approximately 300 p.p.m. $\mathrm{CO}_{2}$ maintained by a buffer solution of $0.2 \mathrm{M} \mathrm{Na}_{2} \mathrm{CO}_{3}: 0.2 \mathrm{M} \mathrm{NaHCO}_{3} 1: 9 \mathrm{v}: \mathrm{v}$ at $0.2 \mathrm{M}$. With this buffer, photosynthesis of leaves from the present parental genotypes, grown in controlled environment rooms as above, was earlier demonstrated to reach light saturation at $15^{\circ}$ C. at about $2000 \mathrm{ft} .-\mathrm{c}$. (Wilson and Cooper, 1969b). In the present experiment, light-saturated photosynthesis was measured at $3000 \mathrm{ft}$. -c. $\left(0.210 \mathrm{cal} . / \mathrm{cm} .{ }^{2} / \mathrm{min}\right.$. of visible radiation $)$. Light-limited photosynthesis was recorded at $400 \mathrm{ft}$.-c. $\left(0.028 \mathrm{cal} . / \mathrm{cm} .{ }^{2} / \mathrm{min}.\right)$. Estimates of mesophyll cell size and thickness were obtained from transverse sections of the appropriate central leaf portions as described in a previous experiment (Wilson and Cooper, 1967). Chlorophyll content of each portion of leaf examined at $400 \mathrm{ft}$.-c. was estimated as described earlier (Wilson and Cooper, 1969).

The 6th and 7th leaves were not always the youngest fully expanded leaves on every plant at the time of sampling, because of different rates of leaf appearance. However, the present sampling method was used for the progeny seedlings because of the marked effect of leaf position on apparent photosynthesis and mesophyll anatomy (Wilson and Cooper, 1969c). In that experiment, there were no effects of difference in the age of fully expanded healthy leaves up to about 18 days.

Rates of photosynthesis of 11 leaf portions only could be examined at any one run in the Warburg apparatus, placing limitations on the sampling procedure. Two runs were conducted each day, using leaves from the first and second block respectively, and 16 runs (8 days) at each light intensity were required to examine all plants. At each run, the 11 plants sampled were selected randomly from the block, with the proviso that no family or parent was represented more than once in each run. Thus, differences within runs did not include differences within families or parents. All 16 runs at $400 \mathrm{ft}$.-c., on 7 th leaves, were conducted subsequent to those at $3000 \mathrm{ft} .-\mathrm{c}$. (6th leaves). Apparent photosynthesis in the stronger light and 
leaf chlorophyll content were expressed in terms both of unit leaf area and of unit mesophyll volume (see Wilson and Cooper, 1969b).

\section{Analysis of data}

Analyses of data from individual plants revealed that variation between $F_{1}$ families and between parents was significantly greater than that within families and parents for every character. Consequently, all genetic analyses of any one character were based on the mean value of all plants in each family or parent, within a block. Run effects were not considered, since these would be common to all families and parents, and would not significantly add to the information obtained from the analyses described below.

Because of the age difference between parents and progeny, two forms of analysis of variance were conducted on each character. The first is due to Hayman (1954a), modified for the half-diallel by Morley Jones (1965), and analyses data from parents and $F_{1}$ families. The second form is that of Yates (1947) and is used here to analyse the $F_{1}$ data only.

Both these analyses partition phenotypic variance into genetic and environmental components. The Hayman (1954a) analysis of the half-diallel with parents is the more sensitive. It can separate genetic variance into additive effects (those fixable by selection) and non-additive effects, and can further detect the presence of dominance and/or non-allelic interaction. On the other hand, the Yates (1947) analysis, where parents are absent, is only capable of partitioning genetic variation into additive and non-additive components.

In the present experiment, a further Hayman (1954a) analysis was conducted on anatomical and morphological data from the diallel by using parental estimates obtained in a previous experiment, grown under the same conditions. These estimates were derived from leaves from standard positions on the main stem rather than young randomly selected leaves (Wilson and Cooper, 1969c). However, no attempt has been made to draw inferences about non-additive effects, in any analysis, in terms of genetic parameters (Hayman, 1954b), since physiological effects of age and/or leaf position on photosynthesis may well be confounded with any absolute difference between parents and progeny, and might thus be reflected in non-additive components of the analysis.

Expectations of mean squares for these analyses depend on the presence or absence of parents and/or reciprocals and on the assumptions made with regard to the parental plant sample. In the present case, the parents were deliberately chosen and cannot be regarded as a random sample from any population, so that the experimental material constitutes the entire population about which valid inferences can be made. The appropriate expectations for this assumption in the two types of analysis used here are given by Griffing (1956a) in terms of general and specific combining abilities (GCA and SCA), and are shown in table 1 . The two estimates of combining ability (GCA and SCA) measure largely additive and non-additive genetic effects respectively (Griffing, 1956b). In the present experiment they are used to provide estimates of heritability in the broad $(H b)$ and narrow $(H n)$ sense (Lush, 1949) for each character, where,

$$
H b=\frac{\sigma_{g}^{2}+\sigma_{g}^{2}}{\sigma_{g}^{2}+\sigma_{s}^{2}+\sigma_{e}^{2}} \quad \text { and } \quad H n=\frac{\sigma_{g}^{2}}{\sigma_{g}^{2}+\sigma_{g}^{2}+\sigma_{e}^{2}}
$$


In calculating heritabilities from Yates analysis data in the present experiment, a pooled error variance (remainder +interaction items) was used for characters where the remainder item was not significant. Thus, in those cases, estimates of $H b$ and $H n$ were the same. Heritability estimates were also obtained from the linear regressions of mid-parent values on progeny means (Falconer, 1960). Comparisons were made between heritabilities calculated from the different analyses.

TABLE 1

Expectations of mean squares for Hayman (1954a) type analysis, including parents and one set of $F_{1}$ 's, and $Y_{\text {ates }}(1947)$ type analysis, one set of $F_{1}$ 's only

$\begin{array}{lc}\text { Hayman Analysis } & \text { Expectation of mean squares } \\ a \text { (parental lines) } & \sigma_{e}^{2}+2(p+2)\left(\frac{1}{p-1}\right) \sigma_{g}^{2} \\ b \text { (mean dominance deviation) } & \sigma_{e}^{2}+2\left(\frac{2}{p(p-1)}\right) \sigma_{s}^{2} \\ \text { Blocks } \times \text { total } & \sigma_{e}^{2} \\ \text { Tates Analysis } & \sigma_{e}^{2}+2(p-2)\left(\frac{1}{p-1}\right) \sigma_{g}^{2} \\ \text { parental lines } & \sigma_{e}^{2}+2\left(\frac{2}{p(p-3)}\right) \sigma_{s}^{2} \\ \text { remainder } & \sigma_{e}^{2} \\ \text { Blocks } \times \text { total } & \\ \text { where } \quad p=\text { number of parents, } & \\ \sigma_{g}^{2} & =\text { general combining ability (largely additive effects), } \\ \sigma_{g}^{2} & =\text { specific combining ability (largely non-additive effects), } \\ \sigma_{e}^{2} & =\text { error variance (largely environmental effects). }\end{array}$

Phenotypic correlations were calculated between all characters in both parental and $F_{1}$ generations. Genetic correlations were also calculated between those characters with high phenotypic correlations, but these agreed with the phenotypic correlations and are not presented here.

\section{Results}

Family mean values for all characters are shown in appendix tables (i) and (ii) in the form of half-diallel tables. Parental values of those characters whose mean estimates were obtained from two sampling methods are shown separately in appendix table (iii).

The results of the Hayman (1954a) analysis of variance for each character are presented in table 2, where parental data were derived from young fully expanded leaves of plants grown together with the $F_{1}$. Comparisons of the interaction variances within each character by Bartlett's test for the homogeneity of variances revealed significant differences $(P<0.05)$ only in cell size, where main effects are therefore tested against their interaction items. In all other characters, each main effect is tested against the block $x$ total interaction $(B \times t)$ item. The significance of item $(a)$ in all characters 
D. WILSON AND J. P. GOOPER

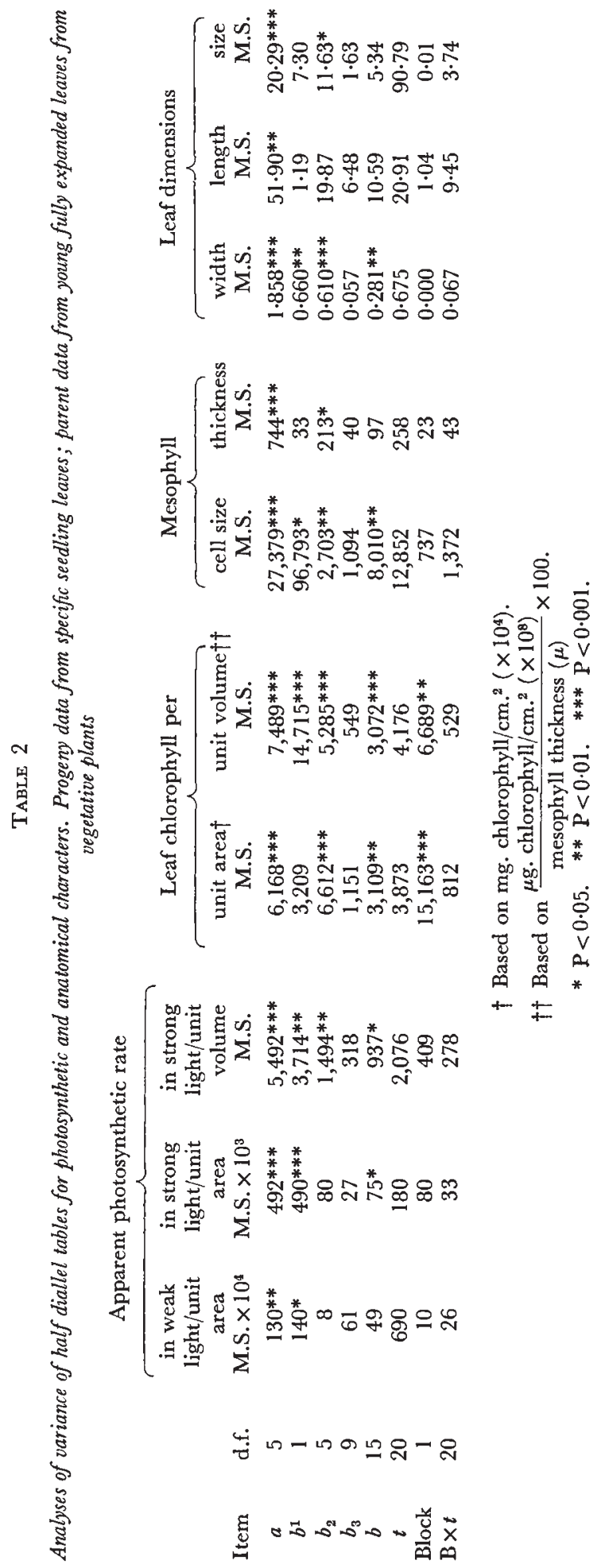


indicates the existence of genetical variation between parental genotypes. The $(b)$ main effect has been split into its component parts; in genetical terms $\left(b_{1}\right)$ is taken as a measure of the mean dominance deviation, $\left(b_{2}\right)$ as a further dominance deviation due to asymmetrical gene distribution, and $\left(b_{3}\right)$ as an estimate of any specific interaction (Hayman, 1954a). However, in the present experiment, significance of $(b)$ items for some characters may well result from physiological effects associated with parental age rather than from genetical effects, as discussed below in the light of the analyses omitting parents. Results from the Hayman analysis where parental data were obtained from an earlier experiment (Wilson and Cooper, 1969c) using 4th and 5th main stem leaves of clonally propagated plants, are shown in table 3. Again, item $(a)$ was significant for all characters. The main difference between these two analyses (tables 2 and 3) lay in the $\left(b_{1}\right)$ and $\left(b_{2}\right)$

TABLE 3

Analyses of variance of half diallel tables for anatomical characters using parent data from standard main-stem leaves

\begin{tabular}{|c|c|c|c|c|c|c|}
\hline \multirow[b]{2}{*}{ Item } & \multirow[b]{2}{*}{ d.f. } & \multicolumn{2}{|c|}{ Mesophyll } & \multicolumn{3}{|c|}{ Leaf dimensions } \\
\hline & & $\begin{array}{l}\text { cell size } \\
\text { M.S. }\end{array}$ & $\begin{array}{c}\text { thickness } \\
\text { M.S. }\end{array}$ & $\begin{array}{l}\text { width } \\
\text { M.S. }\end{array}$ & $\begin{array}{l}\text { length } \\
\text { M.S. }\end{array}$ & $\begin{array}{l}\text { size } \\
\text { M.S. }\end{array}$ \\
\hline$a$ & 5 & $27,392 * * *$ & $754 * * *$ & $1 \cdot 350 * * *$ & $135 \cdot 90^{* * *}$ & $42 \cdot 02 * * *$ \\
\hline$b_{1}$ & 1 & $161,504 * * *$ & 11 & 0.003 & $160 \cdot 46^{* * *}$ & $15 \cdot 05^{*}$ \\
\hline$b_{2}$ & 5 & $27,974 * * *$ & $172 * * *$ & $0 \cdot 144$ & $54 \cdot 38 * *$ & $10 \cdot 34 * *$ \\
\hline$b_{3}$ & 9 & 1,094 & 40 & 0.057 & $6 \cdot 48$ & $1 \cdot 63$ \\
\hline$b$ & 15 & $12,356 * * *$ & $82 * * *$ & 0.082 & $32 \cdot 71 * *$ & $5 \cdot 43^{*}$ \\
\hline$t$ & 20 & 16,115 & 249 & 0.399 & $58 \cdot 50$ & $14 \cdot 57$ \\
\hline Block & 1 & 151 & 16 & $0 \cdot 010$ & $6 \cdot 10$ & 1.04 \\
\hline$B \times t$ & 20 & 1,793 & 8 & 0.062 & $8 \cdot 78$ & $2 \cdot 30$ \\
\hline
\end{tabular}

items for leaf length and width. These items were significant for width but not length when parental data were taken from randomly selected young leaves (table 2), but the opposite situation held when the parental data were taken from a standard leaf position in each genotype (table 3 ). There was a significant difference between blocks in chlorophyll content only (table 2).

Results of analyses of variance omitting parents are presented in table 4. With the exception of leaf length, all main item mean squares were again tested against $B \times t$, because of lack of significant differences between separate interaction items. There were significant parental effects (additive genetic variance) for all photosynthesis measurements, leaf chlorophyll and mesophyll cell size and thickness, but not for any leaf dimensions. There were significant non-additive effects (remainder item) only for photosynthesis in weak light and mesophyll thickness (table 4), in contrast to the situation indicated by the Hayman analysis (tables 2 and 3). There were again significant block effects for chlorophyll content, and also significant differences $(P<0.05)$ between blocks in light-saturated photosynthesis per unit leaf area (table 4).

Heritability estimates for certain characters, particularly in the "narrow" sense, differed markedly depending on the form of the analysis (table 5). Thus, apparent rate of light-saturated photosynthesis per unit leaf area and unit volume had $H n$ values of 0.30 and $0.24 \quad(H b=0.93$ and 0.96$)$ 
D. WILSON AND J. P. COOPER

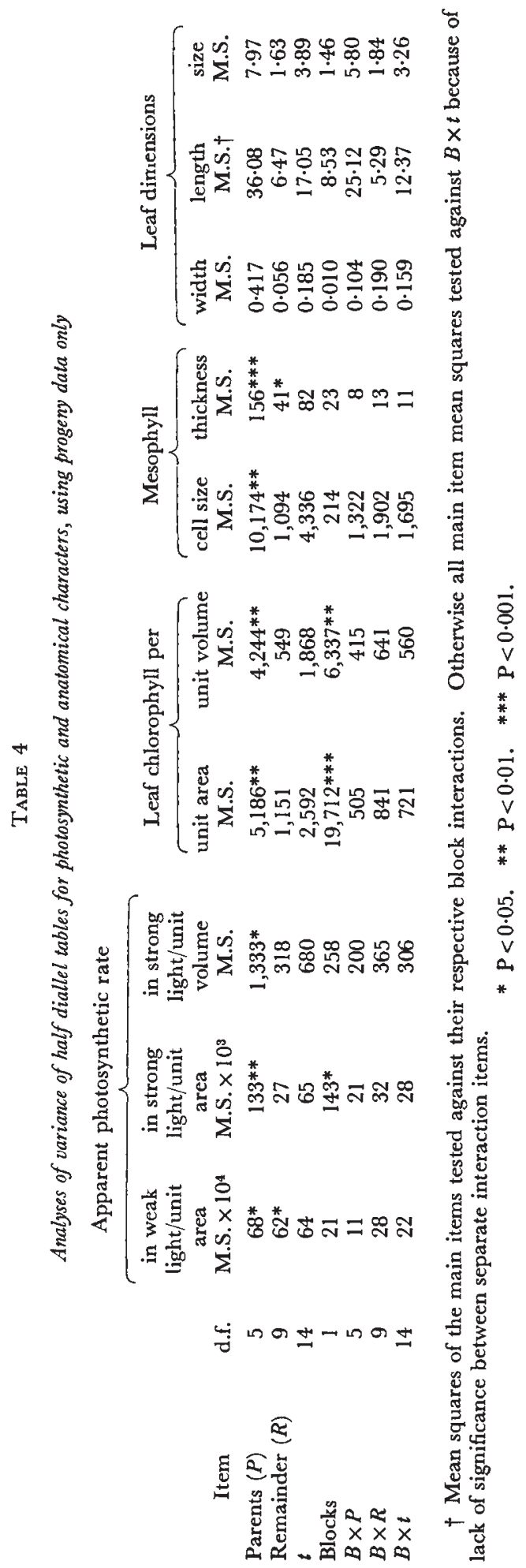


respectively according to the Hayman analysis. However, analysis of progeny data only (Yates, 1947) revealed narrow sense heritabilities of 0.70 and 0.67 respectively (table 5 ). Regression coefficients $(b)$ of mid-parent values on progeny means indicated intermediate heritabilities for these two characters $(0.46$ and 0.35$)$. There were similar disagreements between the Yates and Hayman analyses of mesophyll cell size and leaf chlorophyll. On the other hand, both forms of analysis detected only small $H n$ values for

TABLE 5

Heritability estimates for photosynthetic and anatomical characters $(H b=$ broad-sense heritability; $H n=$ narrow-sense heritability)

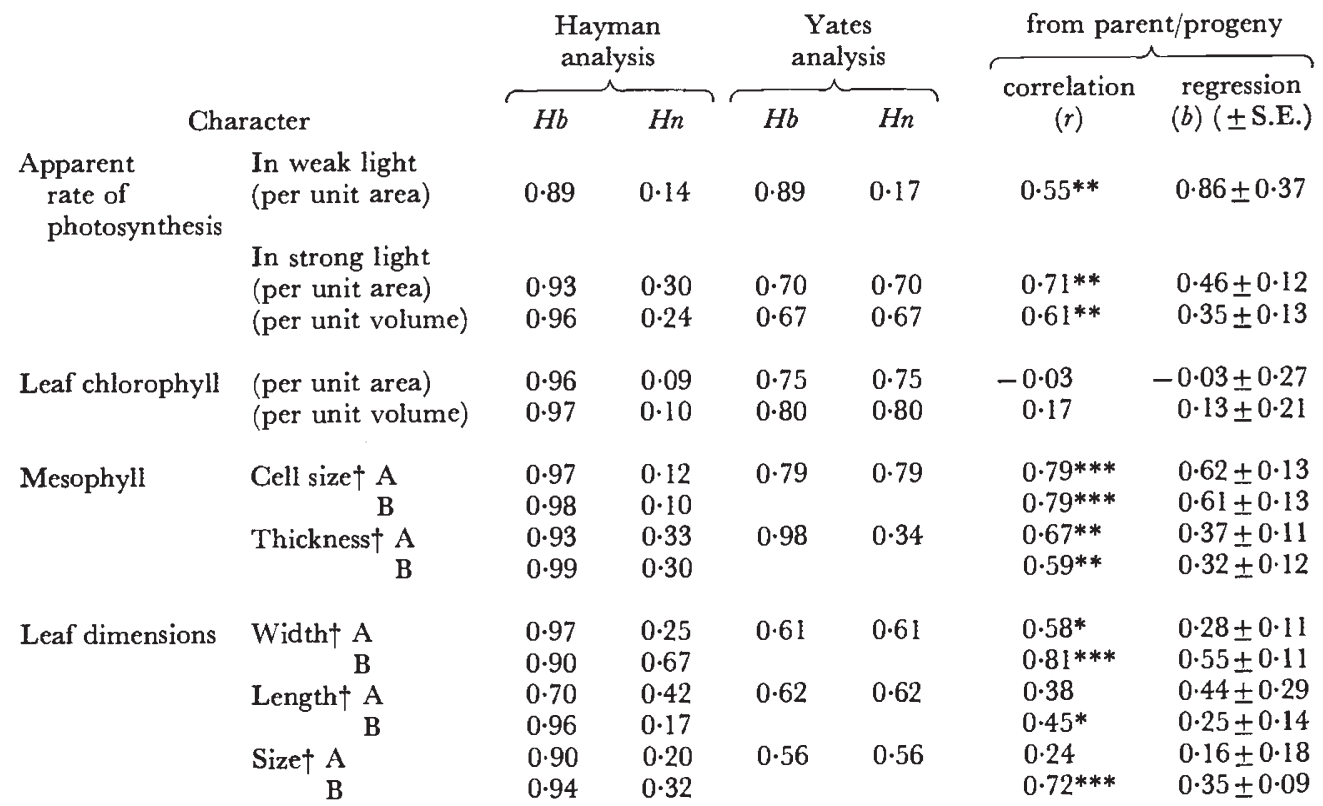

$\dagger$ Using parental data from young fully expanded leaves (A), and leaves from specific main stem positions (B) (Appendix Table (iii)).

$$
* \mathrm{P}<0.05 \text {. ** } \mathrm{P}<0.01 \text {. *** } \mathrm{P}<0.001 \text {. }
$$

photosynthesis in weak light $(0 \cdot 14$ and $0 \cdot 17)$, in spite of a large regression coefficient $(0 \cdot 86)$ of progeny means on mid-parent values. However, the standard error of this coefficient was also large $( \pm 0.37)$ (table 5$)$.

There was good agreement between all methods of estimating heritability for mesophyll thickness, and for leaf width when parental data were obtained from leaves from a standard main stem position, the Hayman, Yates and regression methods providing $H n$ values of $0.67,0.61$ and 0.55 respectively. For leaf length, agreement was best when parental leaves were randomly chosen, giving $0.42,0.64,0.44$ respectively. In general terms, the effect of using parental data from young fully expanded leaves, as opposed to leaves from a standard position, was reflected in differences in the heritabilities for leaf width and length, but not for those of mesophyll characters (table 5).

There were significant correlations between mid-parent values and progeny means for all characters except chlorophyll content, and leaf length and size derived from young randomly selected leaves (table 5). 


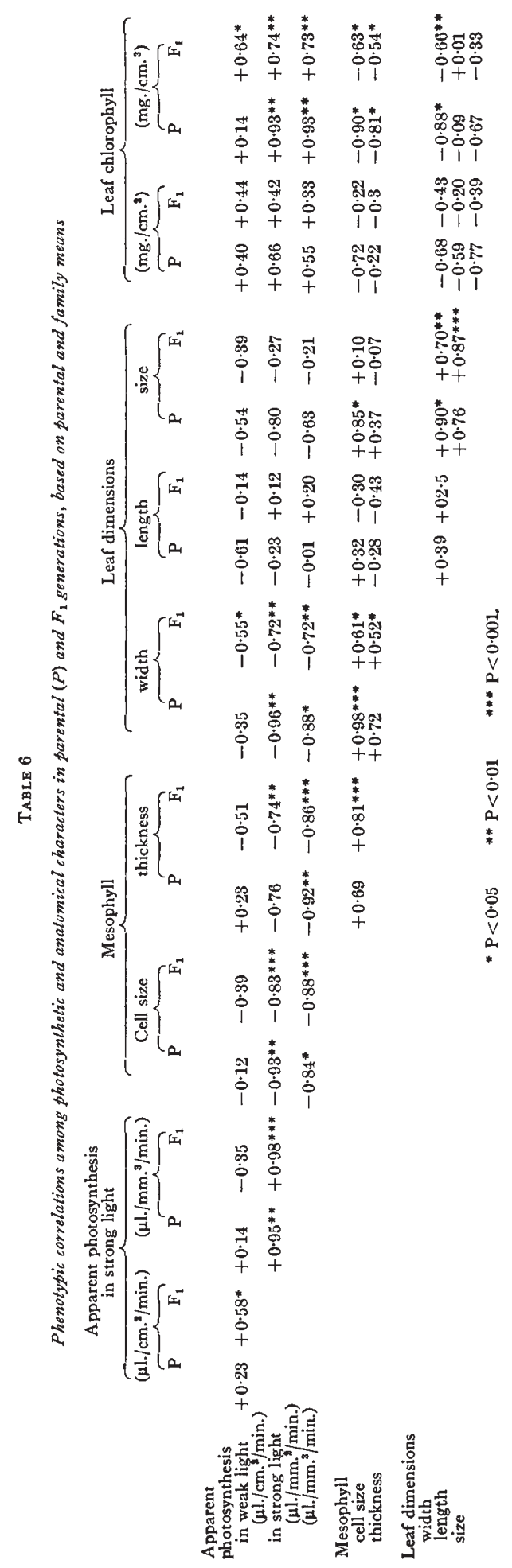


Phenotypic correlations between the present characteristics, among parents and among progeny (table 6), were similar to those found previously among selected Lolium genotypes (Wilson and Cooper, 1969b). Apparent light-saturated photosynthesis was strongly correlated negatively with mesophyll cell size, mesophyll thickness and leaf width, and showed a significant $(\mathrm{P}<0.01)$ positive correlation with chlorophyll content per unit mesophyll volume. Mesophyll cell size was also correlated positively with mesophyll thickness in the $F_{1}$, and with leaf width in both generations. There were significant $(\mathrm{P}<0.05)$ negative correlations between size of mesophyll cells and chlorophyll per unit volume in both generations; chlorophyll was also negatively related to mesophyll thickness and leaf width. Leaf size was significantly correlated with length and width, but length was not significantly related to width. Apparent photosynthesis in low light intensity was weakly correlated $(\mathrm{P}<0.05)$ with light-saturated photosynthesis in the $F_{1}$ generation. Presumably as a result of this, there were also weak correlations $(\mathrm{P}<0.05)$ between leaf width, chlorophyll per unit volume and light-limited photosynthesis (table 6).

\section{Discussion}

There have been no previous attempts to separate genetic variance in photosynthetic activity into additive and non-additive components, nor has any genetic study been made of the present mesophyll characteristics, which have been shown to be closely associated with both apparent light-saturated photosynthesis of selected genotypes and with photosynthetic activity and growth rates of Lolium populations (Wilson and Cooper, 1967, 1969). It is of interest, therefore, to discuss the present results in terms of the genetic assessment of breeding material although, strictly speaking, inferences from the present heritabilities and correlations only apply to the particular six parental genotypes used.

Both forms of variance analysis indicated significant additive genetic variation for all photosynthetic, chlorophyll and mesophyll characteristics (tables 2, 3 and 4). Significant additive effects on leaf length, width and size were revealed only by the Hayman (1954a) analysis. The principal disagreement between the two methods of analysis lay in the detection of non-additive effects. Thus, the analysis which included parental data (tables 2 and 3 ) found significant $\left(b_{1}\right)$ or $\left(b_{2}\right)$ items in all characteristics, whereas when parents were excluded there were significant non-additive components only for light-limited photosynthesis and mesophyll thickness (table 4). Clearly then, the variances in apparent light-saturated photosynthesis, chlorophyll, cell size and leaf dimensions which were ascribed to genetical non-additivity (tables 2 and 3), may well be a result of differences between parents and progeny in plant age and/or leaf position. The existence of a leaf positional effect was suggested by results of the Hayman analyses, when an attempt was made to reduce sampling variation between parents by taking data from leaves from a standard position in each genotype (table 3). Thus, non-additive effects for leaf length disappeared when parental data was taken from randomly chosen young fully expanded leaves (table 2) while the reverse situation was found for leaf width. However, light-limited photosynthesis and mesophyll thickness were much less affected 
by leaf age or position and true genetic non-additivity may well exist for these characters.

Thus, for most anatomical characteristics of the leaf and for lightsaturated photosynthesis, which is associated with mesophyll cell size, the appropriate form of analysis of the diallel is that of Yates (1947), because of the absence of parental material of comparable physiological age to the progeny. On the other hand, for light-limited photosynthesis, which depends mainly on photochemical processes, it appears that randomly chosen leaves from clonally propagated parents may be used to provide parent data for the more sophisticated type of genetic analysis described by Hayman (1954a).

The effects described above are reflected in the respective heritabilities calculated from results of the analyses (table 5). Significant non-additive components in the Hayman analysis have resulted in large differences between "broad sense" and "narrow sense" heritabilities. In the Yates analysis, such difference only appeared for light-limited photosynthesis and mesophyll thickness, where again non-additive components were significant. There was good agreement between the regression of progeny mean on midparent values (using parental data from standard leaves) and heritabilities from the Yates analyses for mesophyll cell size and thickness and leaf width (table 5). The relative order of parental genotypes for these characters was evidently little affected by parental age and/or leaf position. It can be shown from a number of reasonable models that the higher heritability estimates obtained from parent-progeny regression might well be expected, as a result of the relatively inbred nature of the parent clones compared to the variation between them and the presence of unequal gene frequencies at the loci controlling these characters (Jinks, personal communication).

On the basis of the present heritabilities derived from analyses of $F_{1}$ families between six contrasting genotypes from different populations, rapid and immediate response to selection would be expected for light-saturated photosynthesis $(0.70,0.67)$, chlorophyll $(0.75,0.80)$, mesophyll cell size $(0.79)$ and thickness $(0.34)$, and leaf width $(0.61)$ length $(0.62)$ and size $(0.56)$. However, this does not necessarily imply that equally high heritability values or potential response to selection would be obtained within a single ryegrass population.

In spite of the rather low heritability of light-limited photosynthesis shown by both the Hayman $(0 \cdot 14)$ and Yates $(0 \cdot 17)$ analyses, this character is clearly of such practical importance that it might well be a useful selection criterion, particularly in view of the significant $(P<0.01)$ correlation between mid-parent values and progeny means (table 5 ). Furthermore, the correlation between the rates of light-saturated and light-limited photosynthesis was low, suggesting that these two characters might be selected independently.

Phenotypic correlations between the characters (table 6) revealed a similar situation to that obtained previously among ten contrasting Lolium genotypes (Wilson and Cooper, 1969). Thus, in both parental and $F_{1}$ generations, the fastest rates of light-saturated photosynthesis occurred in thin, narrow, leaves with small mesophyll cells and much chlorophyll per unit volume. The rate of light-limited photosynthesis was not associated with any particular anatomical or morphological feature.

In conclusion, although many of the present characters had high herita- 
bilities within the limits of these six genotypes chosen from contrasting populations, it remains to be seen how much response can be achieved to selection from within a single population. However, further work in this Department (Wonkyi-Appiah, personal communication) has revealed heritabilities of about 0.40 for rate of light-saturated photosynthesis, and about $0 \cdot 70$ for leaf dimensions within established ryegrass cultivars.

Furthermore, it is not known whether the strong correlations observed will inevitably lead to marked correlated response to selection. Thus, in populations of $L$. perenne and $L$. multiflorum a strong negative genetic correlation found between leaf size and rate of leaf appearance (Edwards and Cooper, 1963) could be modified by further selection (Edwards, 1967).

\section{SUmmary}

1. A half-diallel cross was performed among six Lolium perenne genotypes from populations of contrasting origin. Progeny were analysed separately and with clonal parental data, and estimates of genetic variances and heritabilities were obtained for photosynthetic rate and related anatomical and physiological characteristics of the leaf.

2. Both forms of analyses revealed significant additive genetic variation for light-saturated and light-limited photosynthesis, for chlorophyll content and for mesophyll cell size and mesophyll thickness.

3. The analysis which included parental data indicated large nonadditive effects for most characters, but this appeared to reflect a difference in age or leaf position between parents and progeny, since the analysis without parents revealed significant non-additive components for light-limited photosynthesis and mesophyll thickness only.

4. Narrow-sense heritabilities from the analysis without parents were high for light-saturated photosynthesis $(0 \cdot 70)$, chlorophyll content $(0 \cdot 75)$, mesophyll cell size $(0.79)$ and thickness $(0.34)$ and leaf width $(0.61)$, but low for light-limited photosynthesis $(0 \cdot 17)$.

5. There was no necessary correlation between the rate of light-saturated and light-limited photosynthesis.

6. Phenotypic correlations indicated that fastest rates of light-saturated photosynthesis occurred in thin, narrow, leaves with small mesophyll cells and much chlorophyll per unit volume.

7. Rates of light-limited photosynthesis were not regularly associated with any particular anatomical or morphological characteristic.

Acknowledgments. -We wish to thank Professor P. T. Thomas, C.B.E., Director, Welsh Plant Breeding Station, for his support and interest in this work. We are grateful to Dr M. D. Hayward for valuable advice and criticism. Thanks are also due to Mrs E. Horzelska for asisstance with the manuscript. This investigation was conducted during tenure of a New Zealand National Research Fellowship held by D. W.

\section{REFERENCES}

BEDDOWS, A. R., BREESE, E. L., AND LEWIS, B. 1962. The genetic assessment of heterozygous breeding material by means of a diallel cross. 1. Description of parents, self and cross fertility and early seedling vigour. Heredity, Lond., 17, 501-513.

Breese, E. L. 1960. The genetic assessment of breeding material. Proc. 8th int. Grassld Congr., 45-69.

COOPER, J. P. 1959. Selection and population structure in Lolium. 1. The initial populations. Heredity, Lond., 13, 317-340. 
COOPER, J. P. 1961. Selection and population structure in Lolium. V. Continued response and associated changes in fertility and vigour. Heredity, Lond., 16, 435-453.

COOPER, J. P. 1963. Species and population differences in climatic response. In: Environmental Control of Plant Growth, ed. L. T. Evans, pp. 381-404. Academic Press, New York.

CORKILL, L. 1950. A comparison of methods of progeny testing for quantitative characters in ryegrass. N.Z. F. Sci. Tech., A32, 35-44.

CoRkill, x. 1956. The basis of synthetic strains of cross-pollinated grasses. Proc. 7 th int. Grassld Congr., 427-431.

Dickinson, A. G., AND JiNks, J. L. 1956. A generalized analysis of diallel crosses. Genetics, $41,65-78$.

EDWARDS, K. J. R. 1967. Developmental genetics of leaf formation in Lolium. II. Analysis of selection lines. Genet. Res., 9, 247-257.

EDWARDS, K. J. R., AND COOPER, J. P. 1963. The genetic control of leaf development in Lolium. 2. Response to selection. Heredity, Lond., 18, 307-317.

FAlCONER, D. s. 1960. Introduction to Quantitative Genetics. Pp. 365. Oliver and Boyd, Edinburgh.

FEJER, s. O. 1960. Selection for high and low productivity in perennial ryegrass (Lolium perenne L.). 1. Heritability study of early generations. N.Z. F. agric. Res., 3, 764-771.

GRIFFING, B. 1956a. Concept of general and specific combining ability in relation to diallel crossing systems. Aust. F. biol. Sci., 9, 463-493.

GRIFFING, B. 1956b. A generalized treatment of the use of diallel crosses in quantitative inheritance. Heredity, Lond., 10, 31-50.

HAYMAN, B. 1. 1954a. The analysis of variance of diallel tables. Biometrics, 10, 235-244.

HAYMAN, B. 1. 1954b. The theory and analysis of diallel crosses. Genetics, 39, 789-809.

HAXWARD, M. D., AND BREESE, E. L. 1968. The genetic organization of natural populations of Lolium perenne. 3. Productivity. Heredity, Lond., 23, 357-368.

JENKIN, T. J. 1931a. The method and technique of selection, breeding and strain-building in grasses. Bull. Bur. Pl. Genet. Aberystwyth, 3, 5-34.

JENKIN, T. J. 1931b. Self-fertility in perennial ryegrass (Lolium perenne L.). Bull. Welsh Pl. Breed. Stn, 12, 100-119.

Jinks, J. L., AND hAYMAN, B. 1. 1953. The analysis of diallel crosses. Maize Genet. Co-op. Newsletter, 27, 48-59.

JONES, R. MORLEY. 1965. Analyses of variance of the half diallel table. Heredity, Lond., 20, $117-121$.

LUSH, J. L. 1949. Heritability of quantitative characters in farm animals. Proc. 8th int. Congr. Genet. Hereditas Suppl., 356-375.

THомas, R. L. 1965. Genetic analysis of climatic races in Lolium. Ph.D. Thesis, Univ. Wales (unpublished).

THOMAs, R. L. 1966. Inter-population variation in perennial ryegrass. 1. Population means. Heredity, Lond., 22, 481-498.

WILSON, D., AND COOPER, J. P. 1967. Assimilation of Lolium in relation to leaf mesophyll. Nature, Lond., 214, 989-992.

WILSON, D., AND COOPER, J. P. 1969a. Assimilation rate and growth of Lolium populations in the glasshouse in contrasting light intensities. Ann. Bot. N.S. (in press).

WILSON, D., AND COOPER, J. P. 1969b. Effect of light intensity and $\mathrm{CO}_{2}$ on apparent photosynthesis and its relationship with leaf anatomy in genotypes of Lolium perenne L. New Phytol., 68, 627-644.

WILSON, D., AND COOPER, J. P. 1969c. Apparent photosynthesis and leaf characters in relation to leaf position and age, among contrasting Lolium genotypes. New Phytol., 68, 645-655.

WILSON, D., TREHARNE, K. J., EAGLES, C. F., AND DE JAGER, J. M. 1969. A manometric technique for determination of apparent photosynthesis of Lolium. F. exp. Bot., 20, 373-380.

YATES, F. 1947. Analysis of data from all possible reciprocal crosses between a set of parental lines. Heredity, Lond., 1, 287-301. 


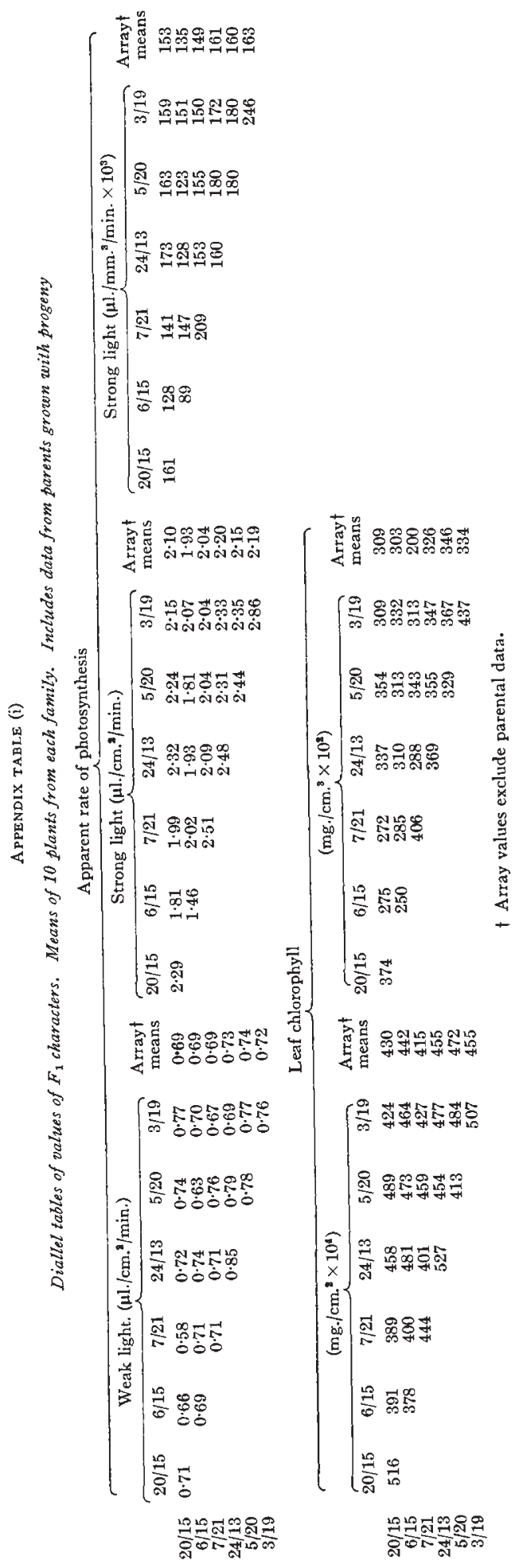




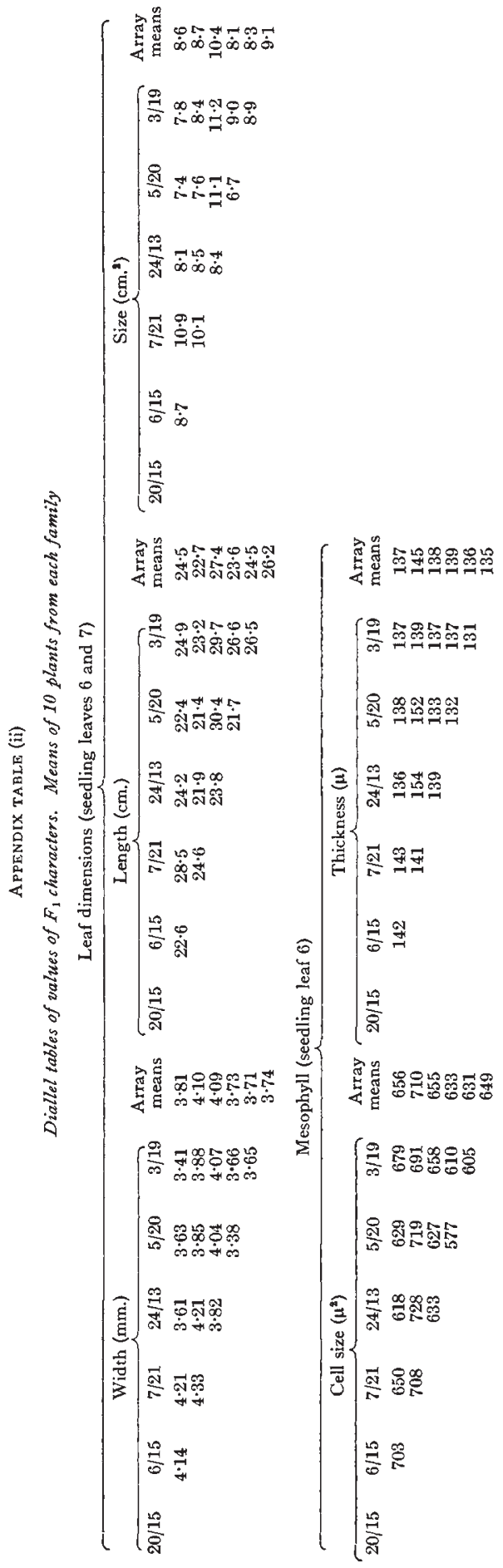


Appendix table (iii)

Alternative parental data used in Hayman (1954a) analysis of variance of half diallel tables for leaf anatomy and morphology

\begin{tabular}{|c|c|c|c|c|c|c|}
\hline \multirow[b]{2}{*}{ Parents } & \multirow[b]{2}{*}{ Leaf source $\dagger$} & \multicolumn{2}{|c|}{ Mesophyll } & \multicolumn{3}{|c|}{ Leaf dimensions } \\
\hline & & cell size $\left(\mu^{2}\right)$ & thickness $(\mu)$ & width (mm.) & length (cm.) & size $\left(\mathrm{cm} .{ }^{2}\right)$ \\
\hline \multirow[t]{2}{*}{$20 / 15$} & A & 501 & 141 & $3 \cdot 7$ & $21 \cdot 7$ & $7 \cdot 5$ \\
\hline & B & 523 & 143 & $3 \cdot 8$ & $20 \cdot 0$ & $7 \cdot 1$ \\
\hline \multirow[t]{2}{*}{$6 / 15$} & $\mathrm{~A}$ & 750 & 165 & $6 \cdot 1$ & 28.4 & $15 \cdot 9$ \\
\hline & B & 686 & 175 & $4 \cdot 7$ & $25 \cdot 0$ & $10 \cdot 7$ \\
\hline \multirow[t]{2}{*}{$7 / 21$} & $\mathrm{~A}$ & 500 & 118 & $3 \cdot 9$ & $32 \cdot 1$ & $11 \cdot 9$ \\
\hline & $\mathrm{B}$ & 568 & 133 & $4 \cdot 7$ & $35 \cdot 0$ & $15 \cdot 3$ \\
\hline \multirow[t]{2}{*}{$24 / 13$} & A & 522 & 159 & $4 \cdot 0$ & $21 \cdot 5$ & $7 \cdot 9$ \\
\hline & B & 461 & 126 & $2 \cdot 8$ & $10 \cdot 0$ & $2 \cdot 5$ \\
\hline \multirow[t]{2}{*}{$5 / 20$} & $\mathrm{~A}$ & 532 & 138 & $3 \cdot 7$ & $23 \cdot 1$ & $8 \cdot 0$ \\
\hline & B & 472 & 140 & $3 \cdot 7$ & $14 \cdot 0$ & $4 \cdot 5$ \\
\hline \multirow[t]{2}{*}{$3 / 19$} & $\mathrm{~A}$ & 490 & 117 & $3 \cdot 3$ & $24 \cdot 4$ & $7 \cdot 4$ \\
\hline & $\mathrm{B}$ & 400 & 119 & $3 \cdot 5$ & $19 \cdot 0$ & $5 \cdot 1$ \\
\hline
\end{tabular}

† A Randomly selected young fully expanded leaves from parental plants grown with the $\mathbf{F}_{1}$.

B Main stem leaves 4 and 5 from previous "leaf position" experiment. Plants grown in the same controlled environment at a different time to the $F_{1}$. 